\title{
Fortalezas y Guerra Santa. Un estudio comparado de algunos aspectos de su funcionalidad en las fronteras de la Cristiandad *
}

\author{
J. Santiago Palacios Ontalva ** \\ Universidad Autónoma de Madrid
}

RESUMEN

En torno a las fortalezas se desarrollaron muchos de los episodios bélicos del secular enfrentamiento medieval entre el Islam y la Cristiandad. En las fronteras orientales y occidentales de estos dos mundos, la arquitectura militar se convirtió en objetivo prioritario de la guerra, al tiempo que constituian bases seguras desde las que operar contra el enemigo. El trabajo que presentamos nos permite acercarnos

a la compleja realidad funcional de estos castillos a la vanguardia de la Guerra Santa, recurriendo para ello a diversos ejemplos de la realidad fronteriza en la Península Ibérica y en Tierra Santa.

\begin{abstract}
In connection with the fortresses were developed many warlike episodes of the secular medieval confrontation among the Islam and the Christendom. In the western and eastern frontiers of these two worlds, the military architecture was converted in a high-priority objective of the war, to the time that constituted secure bases from those which to operate against the enemy. The work that we present allow us an approach to the complex functional reality of these castles to the forefront of the Holy War, appealing for this to various examples of the Holy Land and the Iterian peninsula border reality.
\end{abstract}

* Este trabajo forma parte del Proyecto Órdenes militares y estructuras de poder (Ref. PB960503-C02-02), dirigido por D. Carlos de Ayala Martínez y financiado por la Secretería de Estado de Universidades, Investigación y Desarrollo.

** De forma personal, contamos con el apoyo de una beca de Formación de Personal Investigador, concedida y sufragada por la Comunidad de Madrid. 


\section{PLANTEAMIENTO}

Las fortalezas se hallan unidas indisociablemente a la guerra medieval como uno de sus componentes y protagonistas esenciales. En torno a ellas, o precisamente debido a la necesidad de controlarlas, se libraron numerosos episodios bélicos y operaciones militares de diversa envergadura que conforman una parte importante de nuestra historia medieval. A la hora de ejemplificar de forma elocuente los diversos significantes que las fortalezas adquirieron, consideramos indicado tratar de forma preferente el estudio del secular enfrentamiento entre el Islam y la Cristiandad, contexto histórico que pretendemos acotar cronológica y geográficamente con mayor precisión, pero que, en cualquier caso, nos permitirá esbozar algunas de las muchas facetas funcionales vinculadas a dichas plazas fuertes.

Sin embargo, antes de iniciar nuestra reflexión creemos conveniente determinar mejor algunos conceptos que irán surgiendo a lo largo de las siguientes líneas, tal es el caso de la Cruzada como idea y realidad histórica, sobre todo en relación a sus límites conceptuales, geopolíticos, etc.

Es evidente que no todos los enfrentamientos entre musulmanes y cristianos alcanzaron el calificativo de Cruzada, y que los parámetros teóricos bajo los que una expedición militar se podía considerar como tal, en un sentido estricto - márgenes definidos, no olvidemos, a través de una elaboración intelectual muy posterior a los hechos ${ }^{1}$-, acotan considerablemente el campo de estudio 2 . Pero no es menos cierto, que uno de los impulsos que subyacian detrás de los innumerables episodios violentos que involucraron a miembros de las dos religiones, es esa sacralización de la violencia que forma parte esencial del complejo teórico que conocemos como idea de Cruzada ${ }^{3}$.

1 La historiografía acuñó el término Cruzadas con posterioridad al siglo Xil, vid. TYERMAN, D.J.: "Were there any Crusades in the Twelfth Century?", The English Historical Review, CX (1995), pp. 553-577.

2 Según Gapcía Villoslada, R.: en su Historia de la Iglesia Católica, Madrid, 1968, B.A.C., tomo II, pp. 354-365, únicamente se podrian considerar cruzadas a las guerras predicadas y lideradas por el Papa, en las que los participantes obtendrían la indulgencia plenaria $u$ otras posibles retribuciones espirituales. Sobre dichas recompensas es esencial acudir a los trabajos de FLORI, J.: “Guerre sainte et rétributions spirituelles dans la 2e. moitié du xı. siècle (Lutte contre l'lslam ou pour la papauteé?)", Revue d'Histoire Ecclésiastique, LXXXV n. ${ }^{\circ}$ 3-4 (1990), pp. 617-649, y “Mort et martyre des guerriers vers 1100. L'exemple de la première croisade", Cahiers de civilisation mediévale, XXXIV, n. 134 (1991), pp. 121-139.

3 La más amplia perspectiva del concepto de Cruzada pertenece a ERDMANN, C.: Die Entstehung des Kreuzzugsgedankens, Stuttgart, 1935, cuya traducción al inglés realizaron M.W. Baldwin y W. Gotfart, The origin of the idea of crusade, Princeton, 1977. Otras elaboraciones son las de BLAKE, E.O.: "The formation of the crusade idea", Journal of Ecclesiastical History, XXI (1970), pp. 11-31, y RILEYSMITH, J.: The First Crusade and the idea of crusading, Filadelfia, 1986. Para el caso hispano, es esencial la obra de Goñ GazTAMBIDE, J.: Historia de la Bula de Cruzada en España, Vitoria, 1958. 
Fortalezas y Guerra Santa. Un estudio comparado de algunos aspectos de...

El movimiento cruzado se impregna de violencia desde el momento mismo en el que se considera la expresión más acabada del feudalismo, y se consiguen reconciliar, en un único coricepto, los elementos fundamentales de la caballería más agresiva con aquellos que forman parte de la ideología cristiana ${ }^{4}$. El resultado de tal conjunción fue doblemente beneficioso para la teocracia pontificia, embarcada entonces en un ambicioso programa de reformas que, en su camino en pos de la hegemonía universal, apuntaba hacia la eclesialización de la sociedad del momento ${ }^{5}$. Fue así como se dio un importante paso para la pacificación del convulso Occidente cristiano a través de la vinculación de este fenómeno al movimiento de la Paz de Dios $^{6}$. Pero al mismo tiempo la Iglesia se hacía poseedora exclusiva del privilegio de la guerra justa, guerra ahora considerada santa ${ }^{7}$ gracias un proceso de cristianización de la violencia que había arrancado en san Agustín ${ }^{8}$ y que algunos canonistas, en especial Anselmo de Lucca al servicio de Gregorio VII, se habian encargado de reelaborar en beneficio de los intereses papales ${ }^{9}$, para acabar adjudicando a los dirigentes de la Cristiandad el monopolio de legitimar o arbitrar la violencia sobre la base de unos determinados parámetros políticos o morales.

En su concepción ideológica, en la exteriorización dialéctica de esos conceptos ${ }^{10}$, asi como en su materialización histórica, la lucha contra el Islam constituyó un acto de fuerte carácter violento canalizado hacia objetivos concretos. Desde nuestro punto de vista, las fortalezas condensan gran

4 RILEY-SMith, J.: The First Crusade..., pp. 1-12.

5 Acerca de las raices de esta corriente de espiritualidad y sus más relevantes manifestaciones, vid. Ayala Martínez, C. DE: “Hacia una comprensión del fenómeno cruzado: las insuficiencias del reduccionismo económico", en La Primera Cruzada novecientos años después: el Concilio de Clermont y los origenes del movimiento cruzado, Actas del Coloquio celebrado en Madrid los días 16, 17 y 18 de noviembre de 1995, Castellón, 1997, pp. 167-195, en especial, pp. 174-178 y 183-185.

6 COWDREY, H.E.J.: "The Peace and the Truce of God in the Eleventh Century", Past and Present, 46 (1970), pp. 42-67, reproducido en CowDREY, H.E.J.: Popes, Monks and Crusades, Londres, 1984; DuBY, G.: "The Laity and the Peace of God", en The Chivalrous Society, ed. G. Duby, Londres, 1977.

7 La evolución del concepto de guerra justa hasta llegar a la teoría de la guerra santa cristiana o cruzada es la linea argumental de la obra de Erdmann, y también puede ser seguida en diferentes autores: FLORI, J.: "L'Eglise et la guerre sainte de la "paix de Dieu" a la "croisade" ", Anales E.S.C., 47, n. ${ }^{\circ} 2$ (1992), pp. 453-466; O'CALLAGHAN, J.F.: «The affiliation of the Order of Calatrava with the Order of Citeaux", Analecta Sacri Ordinis Cisterciensis, 15 (1959), pp. 161-193, en concreto p. 175. Sin embargo, otros como H.E. Mayer o Jonathan Riley-Smith, se despegan del discurso de Erdmann y basan sus argumentos sobre el origen de la cruzada en el propio éxito de la peregrinación y conquista de Jerusalén.

8 Vid. MARkuS, R.A.: "Saint Augustine's views of the "Just War"”, en The Church and War (Studies in Church History, XX), Ed. W.J. Sheils, Oxford, 1983, pp. 1-14.

9 Vid. AYala MARTínEZ, C. DE: “Hacia una comprensión del fenómeno cruzado... », pp. 183-185, en concreto nota $n .264$. Sobre este llamado "encauzamiento religios de la violencia", vid. GARcía GuijarRo, L.: Papado, cruzadas y órdenes militares, siglos XI-xil, Madrid, 1995, pp. 40-44.

10 CapITANI, O.: "Sondaggio sulla terminologia militare in Urbano II", Studi Medievah, XXXI, fasc. 1 (1991), pp. 1-25. 
parte de esa violencia y a su vez permiten ejercerla, ya que se pueden considerar como objetivos prioritarios de los ataques, al tiempo que bases desde las que operar militarmente contra el enemigo.

A pesar de todo, la lucha en un contexto fronterizo sólo en ocasiones excepcionales se revistió de los aditamentos propios de una cruzada en sentido estricto ${ }^{11}$, y otras motivaciones estratégicas, militares, políticas o exclusivamente crematísticas ${ }^{12}$, condujeron en la mayor parte de los casos a la guerra en la Edad Media. Desde la posición que nos permitimos adoptar, la guerra santa constituiría un fenómeno heterogéneo en sus manifestaciones externas, atravesado al tiempo de elementos compartidos que consiguen acercar distintas realidades.

En este momento, y en aras de hacer lógico el discurso, creemos imprescindible clarificar otro de los puntos que sostienen el trabajo que presentamos. Nos referimos a este papel protagonista que concedemos a las fortalezas dentro de los diferentes contextos bélicos que vamos a tratar.

Es patente que revestimos de un carácter ejemplar e íntimamente relacionado con la lucha entre la Cristiandad y el Islam, a unos elementos que en otras circunstancias históricas desempeñaron cometidos semejantes, y que definen sus perfiles funcionales no sólo con relación a este enfrentamiento de carácter cruzadista. Sin embargo, si que sostenemos un argumento a favor del empleo paradigmático que hacemos de los castillos, ya que la guerra en la frontera de dos mundos culturales y políticos que se desarrolló en el Oriente Latino así como en la Península lbérica, podrían ser considerados ejemplos acabados de la compleja realidad funcional vinculada a los puntos fuertes del territorio, no sólo en relación a sus capacidades bélicas, sino además acerca de la importancia que adquirieron en la consolidación política de unos espacios muy inestables.

Citados ya los dos ámbitos que nos van a proporcionar el material ilustrativo para nuestras reflexiones, igualmente convendrá delimitar alguros aspectos que han condicionado su uso como ejemplos. En principio, un elemento que podría parecer ventajoso como es la profusión de material historiográfico y de fuentes primarias relativas a los dos contextos es-

11 RILEY-SMITH, por ejemplo, excluye de tal categoria a la lucha mantenida en la Península Ibérica (Vid. What were the Crusades, Londres, 1977, p. 75), frente a posturas como la de Runciman, S.: Historia de las Cruzadas, 3 vols., Madrid, 1997, en concreto vol. I, La Primera Cruzada y la Fundación del Reino de Jerusalén, pp. 98-99, ed. española del original A History of the Crusades, 3 vols., Cambridge, 1951-1954.

12 Las palabras de John France son suficientemente concisas cuando se refiere a los ultramontanos que acudieron a la Peninsula tras la batalla de Sagrajas (1086), pero que prefirieron atacar Tudela en vez de adentrarse en el sur almorávide: "Love of booty drove knights far and wide" (Victory in the East. A military history of the First Crusade, Cambridge, 1994, pp. 12-13). 
pacio-temporales aludidos, se convierte en escollo ante la gran abundancia de obras, autores, referencias y textos, perfectamente utilizables para los fines que perseguimos. Lo más sensato era la elección de las principales figuras historiográficas y de los ejemplos más elocuentes sobre cada tema, sin perseguir nunca una exhaustividad que haría inviable el trabajo.

Otro de los inconvenientes del establecimiento de paralelos históricos puede ser la desincronización de ciertos acontecimientos comparables. Tal circunstancia se produce entre el caso hispano y el oriental, ya que, mientras el siglo XIII significa para los estados cruzados de Ultramar el principio de su fin, en la Península lbérica durante las primeras décadas de esa centuria asistimos a los mayores avances territoriales cristianos, lanzados curiosamente a partir de la campaña de las Navas que constituyó una cruzada investida de todas sus formalidades.

Pero junto a las circunstancias que podrían condicionar el método comparativo, encontramos asimismo factores coincidentes que acercan más que separan las realidades estudiadas. Unos paralelos que comienzan por el carácter semejante del enfrentamiento territorial que se estableció en ambos lugares, tomando como base de dicha conflictividad los numerosos enclaves fortificados que salpican sus geografias.

En un escenario de lucha por el dominio del espacio, no somos los primeros en poner el acento sobre la importancia que tienen los núcleos castrales de un territorio para la efectiva ocupación y dominación del mismo ${ }^{13}$, ni es nuestro objetivo entrar en el frecuentado camino en que se ha convertido el estudio de las dúctiles y permeables fronteras medievales, pero sí que nos gustaría señalar las circunstancias de dos escenarios bélicos de carácter fronterizo con aparentes semejanzas formales. EI "contexto expansivo" del que nos habla García Fitz cuando alude a la situación política del reino castellano leonés con respecto a al-Andalus en-

13 Antes de acudir a otra bibliografia, tengamos en cuenta las palabras de J. GONZÁLEZ, relativas a las tierras castellanas entre el Tajo y Sierra Morena, las cuales "necesitaban primordialmente fortificaciones para su vigilancia y defensa, brindando al menos utilidad para el desarrollo de ganados y algunas labores", en Repoblación de Castilla la Nueva, I, Madrid, 1975, p. 263. Para el ámbito oriental, entre otros testimonios, son rotundas las palabras de C. CAHEN, "Les instruments de l'occupation militaire sont l'armée et les forteresses (...) L'existence de solides forteresses est une nécessité à la fois pour la domination intérieure des Francs, la défense de leurs frontières, l'organisation de bases pour leurs campag. nes", en La Syrie du Nord à l'époque des Croisades et la Principauté Franque d'Antioche, Paris, 1940, p. 328; las de SmAll, R.C.: Crusading Warfare (1097-1193), Cambridge, 1956, p. 24, “The first objective of a invader who came to annex territory was to take its fortified points"; o las de MARSHALL, CH.: "...by retaining control of the strongpoints, the Latins ensured tat they retained control of the region", en Warfare in the Latin East, 1192-1291, Cambridge, 1992, p. 127. Igualmente clarificadoras son las reflexiones de FrancE, J.: Victory in the East..., pp. 26-27; y el ejemplar trabajo de GaRCiA FITZ, F.: Castilla y León frente al Islam. Estrategias de expansión y tácticas militares (siglos Xi-XII), Sevilla, 1998, pp. 172-176 y 198. 
tre los siglos $x \mid$ y $x I^{14}{ }^{14}$, en verdad poco tiene en común con los amenazados territorios cruzados de Oriente, circunscritos a una estrecha franja costera entre las montañas y el Mediterráneo. Pero, tanto si hablamos de unas necesidades prioritariamente ofensivas como si nos referimos a dinámicas defensivas - por otro lado alternas con suma facilidad-, tampoco deja de ser patente la compartida pretensión de controlar el mayor número de fortificaciones como medio para cubrir una necesidad de estabilidad.

Tampoco resultan muy divergentes las coyunturas político-territorial castellana y cruzada durante el periodo indicado, en relación a la dicotomía geográfica impuesta entre una terra Christianorum y una terra Sarracenorum ${ }^{15}$, espacios en contacto permanente y caracterizados por la densidad de fortalezas que atesoraron, aunque gran parte de la efectividad de dichos enclaves en relación a la defensa de esos límites se venga poniendo en duda desde hace tiempo ${ }^{16}$.

Por último, no podemos olvidar otro de estos rasgos compartidos, como es la escasez de efectivos humanos a la que se enfrentaron por igual castellanoleoneses y francos dentro de sus correspondientes territorios de expansión, un factor que determinará considerablemente numerosos aspectos de la dinámica bélica y colonizadora llevada a cabo por dichos protagonistas. Las limitaciones demográficas influyeron, sin duda, en la composición de los ejércitos de campo que se enfrentaron a las fuerzas musulmanas tanto orientales como andalusies, las cuales por su parte, en pocas situaciones sufrieron esa penuria de combatientes. Pero a la suerte en el campo de batalla, hemos de añadir que la capacidad defensiva u ofensiva de una fortaleza estuvo asimismo influida por el tamaño de su guarnición, y sobre todo hemos de advertir que la carencia de un número suficiente de personas involucradas en este contexto fronterizo fue el origen de ciertos sucesos de fondo. Nos referimos, por una parte, a que la escasa cantidad de francos asentados en los principados latinos en Oriente Próximo provocó que dichos estados fueran incapaces de progre-

14 Garcia FITZ, F.: Castilla y León frente al Islam..., p. 204.

15 Chronica Adefonsi Imperatoris, edición y estudio por Luis Sánchez Belda, Madrid, 1950, p. 30; Crónica del Emperador Alfonso VII, edición, traducción, notas e índices de Maurilio Pérez González, León, 1997, p. 108.

16 Mientras que para el caso hispano ha sido el profesor F. García Fitz quien ha manifestado dudas razonables al respecto de la operatividad efectiva de posibles sistemas defensivos orgánicos, basados en la presencia de fortalezas en un territorio concreto, vid. Garcia FITZ, F.: «Fortificaciones, fronteras y sistemas defensivos en al-Andalus, siglos X|-X|II', en / Congreso Internacional. Fortificaciones en al-Andalus, Algeciras, 1996, pp. 269-280; ID.: Castilla y León frente al Islám, pp. 190-203; el papel de los castillos en las fronteras de los territorios latinos ha sido acotado por Small, R.C.: "Crusaders' Castles of the Twelfth Century", Cambridge Historical Journal, X, 2 (1951), pp. 135-137; ID.: Crusading Warfare..., pp. 60-62 y 204-209; y MARSHAL, Ch.: Warfare in the Latin East..., pp. 129-130. 
Fortalezas y Guerra Santa. Un estudio comparado de algunos aspectos de...

sar en su expansión territorial hacia el interior de Siria ${ }^{17}$, y que a medio plazo estuvieran envueltos en una situación de amenaza crónica por parte de los emires musulmanes. Por otro lado, no menos relevante fue la limitación demográfica en el avance casteliano hacia el sur, lento y lleno de dificultades, entre otras causas debido a la falta del material humano necesario para sostener la defensa y colonización de las nuevas tierras, bases asentadas en los primeros momentos de la conquista alrededor de los enclaves castrales.

A pesar de todo, en el seno de dos escenarios bélicos en los que primaba una estrategia defensiva, inserta en el más holgado concepto de guerra de posiciones ${ }^{18}$, el éxito de tal modo de actuar desde seguros propugnáculos residia más en la propia materialidad física de esa arquitectura defensiva y en la alta densidad de construcciones militares sobre un espacio ${ }^{19}$, que en el número de defensores que integraban las correspondientes guarniciones, generalmente reducidas, si exceptuamos las grandes ciudades y las plazas fronterizas más expuestas 20 .

\section{APROXIMACIÓN A UNA REALIDAD MULTIFUNCIONAL}

Frente al tradicional valor que poseía la arquitectura militar medieval como elemento paradigmático de un mundo en constate amenaza, y que por lo tanto precisaba de las propias fortalezas para su defensa, son cada vez más las voces y los argumentos que otorgan a las construcciones castrales nuevas facetas funcionales ajenas ya, o todavía vinculadas a la violencia medieval. Han surgido, por lo tanto, numerosas reflexiones entre historiadores y arqueólogos que abogan por ese carácter multifun-

17 "The crusading states were never really strong enough to complete the conquest of Syria (...) Want of numbers, them, was the realcause of the failure of the Franks to conquer inner Syria", en OMaN, Ch.: A History of the Art of War in the Middle Ages, I, Nueva York, 1924, pp. 254 y 256.

18 Garcia FITZ, F.: Castilla y León frente al Islam..., pp. 172 y ss; cfr. FRANCE, J.: Victory in the East..., pp. 26-27.

19 GaRCia FiTZ, F.: Castilla y León frente al Islam..., pp. 185 y 199.

20 Evidentemente las cifras varian de manera ostensible entre las manejadas para las fortalezas peninsulares y las que se estiman para los castillos cruzados. En el primer caso los defensores sumarian unas pocas decenas, vid. GARCiA FITZ, F.: Castilla y León trente al Islam..., p. 195; FOREY, A.: "The Military Orders and the Spanish Reconquest in the twelfth and thirteenth centuries", Traditio, XL (1984), reeditado en Military Orders and Crusades, Variorum, 1994, p. 210; ID.: The Military Orders. From the Twelfth to the Early Fourteenth Centuries, Londres, 1992, pp. 70-71. Mientras, para los enclaves francos las apreciaciones de $\mathrm{Ch}$. Marshall llegan a las dos mil personas en el caso del Crac, y entre esta cifra y el miliar de guerreros en los casos de Safed, Qalat Marqab o Monte Tabor, vid. MARSHALl, Ch.: Warfare in the Latin East..., pp. 117-121, en especial p. 119; también ForEY, A.: The Military Orders..., pp. 68-69. 
cional atribuible a las fortalezas ${ }^{21}$, aunque quizás sea necesario hacer hincapié en el sentido de estos edificios, no sólo como bastiones defensivos de un espacio concreto y sobre todo como referencia protectora de los pobladores de dicho territorio, sino como estructuras físicas y psicológicas capaces de intervenir activamente en operaciones ofensivas contra el enemigo ${ }^{22}$.

En el estudio de algunos aspectos de esta doble vertiente práctica de la arquitectura militar se centrarán nuestras siguientes palabras, en torno a la concepción de las fortalezas como objetivos militares prioritarios, y acerca del empleo de esos mismos puntos fuertes como medios para la consecución de diferentes fines estratégicos. En síntesis, nos referiremos a algunas de sus capacidades defensivas y ofensivas.

\subsection{Los castillos como objetivos. Estrategia defensiva}

En tanto que objetivos militares, es indudable que los castillos involucrados en la guerra santa no presentaron especiales caracteres ni diferencias substanciales con el resto de las fortalezas medievales, aunque no podemos despreciar la importancia cualitativa de alguna de ellas y la acumulación de edificaciones castrales en aquellos territorios en disputa con el Islam. De cualquier forma, como hemos visto, en torno a su posesión o control giraron la mayor parte de las actividades militares del periodo, y los puntos fuertes de un territorio se pueden considerar, por tanto, como objetivos prioritarios de muchas iniciativas políticas, bien porque coincidan con lugares estratégicos o grandes ciudades, o por la necesidad básica de tomar las principales plazas de un espacio como medio para su dominación.

21 Un trabajo que se puede calificar de clásico es el de AYALA MARTinEZ, C. DE: “Las fortalezas castellanas de la orden de Calatrava en el siglo XII», En la España Medieval, 16 (1993), pp. 9-35, particularmente clarificador acerca de las diferentes facetas funcionales que confluyeron en las fortificaciones medievales _ _en concreto en los enclaves bajo poder calatravo durante el siglo X॥-. Además vid. $C_{A-}$ HEN, C.: La Syrie du Nord..., p. 328; Evdoux, H.-P.: Les Châteaux du Soleil. Forteresses et guerres des Croisés, París, 1982, p. 229; FOREY, A.: "The Military Orders and the Spanish Reconquest...", p. 218.

22 Siguiendo las líneas de la historiografía anglosajona en el análisis funcional de los castillos, pero aplicando ese enfoque al caso peninsular F. GARcía FITz concluye: “Así pues, en las fortalezas, la función protectora e integradora del espacio, y la función ofensiva constituyen dos vertientes de una misma realidad militar que, lejos de ser contrapuestas, resultan plenamente complementarias. El despliegue de esta multifacética funcionalidad convirtió al castillo en el eje de una estrategia concebida para el control del espacio y para la ampliación del dominio..." (GAAClA FITZ, F.: Castilla y León frente al Islam..., p. 215). SMAlL ya afirmaba por su parte: "The castles were also the instruments of conquest and colonizatión...", en "Crusaders' Castles of the Twelfth Century", p. 149. 
Sin embargo, cuando consideramos estos enclaves como elementos capitales de la dinámica bélica lo hacemos, en gran medida, apelando a un sentido marcadamente defensivo de la arquitectura castral, es decir, inclinándonos por su faceta pasiva o negativa ${ }^{23}$ dentro del teatro de operaciones, función elemental aunque no la única posible ${ }^{24}$.

En un plano práctico, las tareas defensivas concretas que se asumieron desde ciertas fortificaciones abarcan un amplio conjunto de acciones que sintetiza la expresión "guardar la tierra", extraída del Setenario de Alfonso X ${ }^{25}$, y que constituye toda una declaración de intenciones políticas en la que la erección de "los castiellos e las fortalezas» jugaban un papel protagonista.

Algunos documentos son igualmente gráficos al considerar a las órdenes militares y sus castillos como "muro y escudo para la defensa de la Cristiandad 26 , defensa en la que estas instituciones desempeñaron una labor destacada en los lugares más amenazados de las fronteras peninsulares y orientales ${ }^{27}$, a pesar de las dudas que plantea Smail para el caso de la Siria latina acerca de su eficiente colaboración en el sostenimiento de los estados cruzados ${ }^{28}$.

La capacidad defensiva de los enclaves castrales se puso a prueba con ocasión de muy diversas circunstancias dentro de una guerra de constantes

23 Clausewirz, C. von: De la Guerra, 1 . $^{a}$ ed., 1831, reeditado por la Ed. Ejército, Madrid, 1980 , pp. 385-386. Siguiendo los pensamientos del general prusiano, la estrategia defensiva, de la que forman parte las construcciones militares medievales, tendrian un objetivo negativo. Por contra, el ataque en su sentido de avance territorial y de conquista posee un acento positivo.

24 A pesar de la multifuncionalidad propuesta es cierto, sin embargo, que detrás de la construcción de alguna significativa fortaleza se puede vislumbrar una mayor inclinación defensiva. Es el caso, por ejemplo, del castillo del Milagro, erigido en 1214 por Rodrigo Jiménez de Rada para la defensa de Toledo por el sur (GonzáLEZ, J.: El reino de Castilla en época de Alfonso VIII, 3 vols., III, Madrid, 1960 , doc. n. 9 965, pp. 666-668 [en adelante Alfonso VIII]), y el de no pocas fortificaciones francas situadas en las zonas más amenazadas de la frontera, cuyo mantenimiento con explícitas menciones a su caracter defensivo se hace prioritario (Vid. SmAlL, R.C.: Crusading Warfare.., p. 208).

25 Setenario de Alfonso el Sabio, edición e introducción de K. H. Vanderford, Barcelona, 1984, Ley X, p. 16 (2.a ed. con estudio preliminar de R. Lapesa). Vid. AYALA MARTínEZ, C. DE: «Fortalezas y creación de espacio político: la Orden de Santiago y el territorio conquense (siglos XII-Xili)", Meridies, II (1995), p. 23.

26 FOREY, A.: "The Military Orders and the Spanish Reconquest...", p. 212, vid. GonzAlEZ, J.: Alfonso VIII, II, doc. n. 2 200, pp. 331-332; III, doc. n. ${ }^{2}$ 641, pp. 139-141.

27 A. Forey acentua este cometido llevado a cabo por las órdenes " in sarracenorum frontariam defendendo et hedificiis et militibus muniendo" (FOREY, A.: "The Military Orders and the Spanish Reconquest...", pp. 202 y 212, vid. GonzALEZ, J.: Alfonso VIII, III, doc. n. ${ }^{2} 1008$, pp. 734-736). En Tierra Santa, cuya defensa radicaba en el poder de la fortificación del territorio, también las órdenes destacaron en la defensa de muchas de las plazas, pero además, en repetidas ocasiones la concesión a estas instituciones de una fortaleza estuvo acompañada de una cláusula para la reparación, mejora o en su caso construcción de un castillo (ID.: Ibidem, pp. 62-65).

${ }^{28}$ SmAll, R.C.: “Crusaders' Castles of the Twelfth Century", pp. 147-148, páginas en las que partiendo de sus reticencias para integrar a las órdenes en la dinámica feudal de ultramar, llega a dudar de la capacidad defensiva de estas instituciones militares. 
asedios y maniobras de castigo del territorio enemigo. Pero nos parece apropiado destacar algunos casos paradigmáticos del periodo, en los que con más nitidez se aprecia esa fijación por las fortificaciones que se dio en los enfrentamientos entre cristianos y musulmanes.

Resulta relevante, por ejemplo, que la primera de las operaciones militares peninsulares que reúne, según algunos especialistas ${ }^{29}$, las condiciones de una cruzada con todas sus sanciones, sea la campaña de Barbastro (1064-1065) ${ }^{30}$, en la que una hueste internacional se lanzó contra dicha fortaleza aragonesa hasta su conquista por asedio. Se trató de un movimiento focalizado y dirigido contra una ciudad bien fortificada en el que se involucraron contingentes heterogéneos, pero que precisamente debido a esa excepcionalidad no tuvo el éxito previsto ya que, pocos meses después cuando la mayor parte de los caballeros habían regresado a sus tierras, los musulmanes de Zaragoza recuperaban la fortaleza en un nuevo episodio característico de la lucha fronteriza. Esta campaña, que revistió gran importancia en su momento si atendemos a las referencias que de ella hicieron algunas crónicas musulmanas y cristianas ${ }^{31}$, se nos presenta por tanto, como un episodio importante de la reconquista y ejemplifica de alguna forma una particular visión de los puntos fuertes del territorio como objetivos políticos, estratégicos y simbólicos.

29 Existe un amplio debate sobre la consideración de la conquista de Barbastro como la primera cruzada hispana, desde posturas favorables como las iniciadas por BoIsSONNADE, P.: "Cluny, la papauté el la première grande croisade internationale contre les Sarrasins d'Espagne: Barbastro (10641065)", Revue des Questions Historiques, 117 (1932), pp. 257-301; ID.: “Les premières croisades françaises en Espagne: Normands, Gascons, Aquitains, et Bourguignons (1018-1032)", Bulletin hispanique, 36 (1934), pp. 5-28; Runciman, S.: Hisioria de las Cruzadas..., I, pp. 98-99; o Goñı GaZTAMBIDE: Historia de la Bula de Cruzada..., pp. 43-62; hasta los extremos opuestos donde podemos encontrar a ALPHANDÉRY, P., y DUPRONT, A.: La Cristiandad y el concepto de Cruzada. Las primeras cruzadas, México, 1959 (1. ed. francesa, París, 1954), pp. 27-29; y Rousset, P.: Les Origines et les Caractères de la Première Croisade, Neuchâtel, 1945, p. 53.

30 La más cercana revisión de este acontecimiento y de la historiografía generada en torno a él corresponde a FERREIRO, A.: "The siege of Barbastro 1064-1065: a reassessment", Journal of Me dieval History, 9 (1983), pp. 129-144, aunque es mucho más reciente parte de la obra de SENAC, P.: La Frontière et les Hommes (vile.-xile. siècles). Le peuplement musulman au nord de l'Ebre et les débuts de la reconquête aragonaise, 2000, que dedica un capítulo a "La trontière en mouvement: L'expédition de Barbastro".

31 IBN 'L DARI, La caida del califato de Córdoba y los Reyes de Taifas (al-Bayan al-Mugrib), estudio, traducción y notas por F. Maíllo Salgado, Salamanca, 1993, pp. 188-190, 211 y 218; Al-Hulal alMawśiyya. Crónica árabe de las dinastias almorávide, almohade y berimerín, traducción de A. Huici Miranaa, Tetuán, 1951, p. 89, BosCH VILA, J.: "Al-Bakri: dos fragmentos sobre Barbastro en el "Bayan Al-Mugrib" de lbn Idari y en el "Rawad Al-Mi 'Tar" de Himyari", Estudios de la Edad Media de la Corona de Aragón, 3 (1947-1948), pp. 242-261; además de algunas referencias en los textos de Ibn Hayyan (Vid. Ferreiro, A.: "The siege of Barbastro...", p. 131). En cuanto a los numerosos textos narrativos cristianos que mencionan la campaña de Barbastro, es recomendable de nuevo acudir a la bibliografía aportada y consultada por A. Ferreiro (pp. 143-144), donde aparecen fuentes aragonesas, francesas e italianas al respecto. 
Fortalezas y Guerra Santa. Un estudio comparado de algunos aspectos de...

Las fortalezas han sido objeto de disputa permanente y su control se convirtió en meta de muchas acciones militares integrantes de estrategias parciales de hostigamiento del espacio fronterizo enemigo, o considerando a estos puntos como ejes capaces de cristalizar una conquista firme ${ }^{32}$. Así, fueron innumerables los movimientos en uno $u$ otro sentido, pero nos interesa destacar ahora algunos momentos en los que se evidenció el grado de importancia que revestían los castillos en diferentes contextos de guerra santa.

El propio avance de los contingentes cruzados desde Asia Menor hacia Jerusalén constituye un recorrido jalonado de conquistas por asedio de grandes ciudades fortificadas, como Nicea o Antioquía ${ }^{33}$, cuya posesión otorgó a los francos el dominio de sus correspondientes espacios de influencia. Pero esta evidente necesidad de ocupar las principales fortalezas se repite significativamente en dos ocasiones - de forma paralela entre el caso hispano y latino-, como consecuencia de dos relevantes derrotas de las armas cristianas. Nos referimos a las batallas de Alarcos (1195) y Hattín (1187), tras las cuales cayeron en poder musulmán gran número de castillos y se quebrantaron, por tanto, todos los posibles mecanismos que protegían las fronteras más amenazadas de la Cristiandad.

La principal consecuencia de la ruptura de treguas con los almohades, provocada por Alfonso VIII con su política intransigente y belicosa iniciada en los primeros años de la década de los noventa fue la desastrosa jornada de Alarcos ${ }^{34}$, que supuso la pérdida de la mayor parte del Campo de Calatrava ${ }^{35}$.

32 GARCIA FITZ, F.: Castilla y León frente al islam..., pp. 127-136, habla de "pequeñas cabalgadas" o de "grandes incursiones", aunque en tal clasificación los criterios definitorios no son los objetivos finales perseguidos, sino la diferente organización táctica y capacidad destructiva de los contingentes involucrados. Así, las operaciones del primer tipo no tendrían capacidad real de menoscabar los fundamentos económicos, políticos o militares del enemigo, algo que si podían conseguir las incursiones de mayor profundidad.

33 Vid. Bradbugy, J.: The Medieval Siege, Woodbridge, 1992, pp. 108-114; Runciman, S.: Historia de las Cruzadas..., I, pp. 173-179 y pp. 206-225.

34 Las mejores sintesis acerca de la batalla siguen siendo los trabajos de GonzÁLEZ, J.: Alfonso VIII, I, pp. 952-970 y Repoblación..., I, pp. 235-238; aunque es conveniente acercarse a varios de los textos presentados en el congreso Alarcos 1195 (Alarcos 1195. Actas del Congreso Internacional Conmemorativo del VII Centenario de la Batalla de Alarcos, Coords. R. Izquierdo Benito y F. Ruiz Gómez, Cuenca, 1996), asi como a la obra de Rodriguez-PiCAVEA, E.: Las Órdenes Militares en la frontera. La contribución de las Órdenes a la delimitación de la jurisdicción territorial de Castilla en el siglo xil, Madrid, 1994, pp. 99 y ss. Vid. también ARIAS BAUTISTA, M. ${ }^{\text {a }}$ T.: "El desmoronamiento de la frontera sur tras Alarcos", Ejército, 643 (1993), pp. 70-76.

35 Consecuencias nefastas a pesar de las disposiciones de Alfonso Vill para que se reforzara el castillo de Alarcos, y pese a que el maestre Nuño Pérez de Quiñones “... hizo reparar y fortalecer las torres y cercas de Calatrava la vieja (...) Otrosi entendio en bastecer los castillos de Caracuel y Benavente y los otros de aquella tierra”, RADES Y ANDRADA, F. DE: Chronica de las tres Ordenes y Cauallerias de Santiago, Calatrava y Alcántara, Chronica de Calatrava, Toledo, 1572 (ed. facsimil, Valencia 1997) fols. $19 v-20 r$ 
A la inmediata conquista de Alarcos por parte almohade ${ }^{36}$, hemos de añadir la capitulación de las fortalezas de Caracuel, Calatrava, Benavente, Malagón y la torre de Guadalerza ${ }^{37}$, aunque es probable que la nómina completa fuera más extensa, y que por otro lado los freires calatravos mantuvieran en su poder castillos como el de Piedrabuena, Dueñas y Chillón, enclaves alejados de las rutas seguidas por las tropas norteafricanas ${ }^{38}$. Tales daños en tan dilatada extensión territorial, que sin duda constituía la vanguardia de Castilla contra el Islam, produjo un considerable retroceso de la frontera hasta las posiciones del entorno del Tajo, con la consiguiente amenaza para Toledo y el resto de ciudades de la Transierra.

Ante la ineficacia demostrada por la densa malla castral que presentaba la comarca, no quedó otra alternativa que la del repliegue hacia enclaves seguros, mientras los almohades se dedicaban a tomar diferentes castillos en un proyecto de consolidación de sus conquistas que a la postre resultó poco efectivo ${ }^{39}$. En las difíciles circunstancias que siguieron a esas importantes pérdidas territoriales y militares podemos encontrar, sin embargo, el origen de la exitosa reacción cristiana de las primeras décadas del siglo XIII 40 .

No menos traumáticos fueron los acontecimientos bélicos que siguieron a la batalla de Hattín, en la que fue barrido del terreno la mayor parte del ejército franco estacionado en Oriente ${ }^{41}$, y a consecuencia de la cual los escasos defensores que habían permanecido guarnecidos tras los muros de muchas fortalezas, no pudieron hacer nada por evitar el estrepitoso derrumbamiento defensivo que se produjo. De esa forma, como frutos madu-

36 "Despues de todo esto, los Moros pusieron cerco al castillo de Alarcos, que era muy fuerte: y dentro de pocos dias le tomaron por combate...", RADES y ANDRADA, F. DE: Chronica de Calatrava, fol. $20 \mathrm{v}$.

37 Crónica Latina de los Reyes de Castilla, introducción, texto crítico, traducción, notas e índices de L. Charlo Brea, Cádiz, 1984, pp. 8 y 15; RADES, F. DE: Chronica de Calatrava, fols. 20v-21r., no especifica más que la capitulación de Alarcos y Calatrava la Vieja, aunque se refiere a que «la Orden yua ya muy de cay'da, con auerse perdido tantas y tan buenas Villas con sus Castillos en el Campo de Calatravan (fol. 21r.).

38 Vid. González, J.: Repoblación..., I, pp. 235-236.

39 La hueste vencedora permaneció muy poco tiempo en campaña y parece que no amortizó convenientemente la victoria (GARCIA FITZ, F.: Castilla y León frente al Islam..., p. 309).

40 Para muchos cronistas medievales la derrota de Alarcos estaría en el origen de la campaña de las Navas, vid. JIMENEZ DE RADA, R.: Historia de los hechos de España, edición, traducción, notas e índires de Juan Fernández Valverde, Madrid, 1989, libro VII, cap. XXXIV, p. 304; Crónica Latina..., p. 23; LuCAS DE TUY: Crónica de España por Lucas, obispo de Tuy, ed. de J. PuYOL, Madrid, 1926, libro IV, cap. XXXIII, pp. 412-413; y ALFonso X: Primera Crónica General de España, editada por R Menéndez Pidal y D. Catalán, Madrid, 1977, cap. 1007, p. 686.

41 Vid. Runciman, S.: Historia de las Cruzadas... II, pp. 394-426; Small, R.C.: Crusading Warfare... pp. 189-203; PRAWER, J.: “La bataille de Hattin», Israel Exploration Journal, 14 (1964), pp. 160-179; ID.: Crusader Institutions, Oxford, 1980, pp. 484-500; LyONS, M.C., y JACKSON, D.E.P.: Saladin: The Politics of the Holy War, Cambridge, 1982; aunque más reciente es el trabajo de KEDAR, B.Z.: "The Battle of Hattin Revisited", en The Horns of Hattin, ed. B.Z. Kedar, Jerusalén, 1992, pp. 190-207. 
Fortalezas y Guerra Santa. Un estudio comparado de algunos aspectos de...

ros fueron cayendo en manos de Saladino muchos de los castillos y ciudades fortificadas de la región, aunque algunos historiadores y biógrafos del sultán han criticado su negligente actuación tras la batalla, al dejar en manos cristianas los más importantes centros estratégicos - caso de Tiro y otras grandes fortalezas-, que funcionaron como centros de resistencia durante la tercera cruzada ${ }^{42}$.

La lista de estos enclaves recuperados como consecuencia de la victoria musulmana es larga y no es nuestra intención ser exhaustivos, pero es destacable que el impulso de los vencedores fue tan demoledor, que en pocas semanas fueron capitulando primero las fortalezas de Galilea -Tiberíades, Nablus, Gaza, Ascalón y la mismísima ciudad de Jerusalén-, después algunas de la costa del actual Libano - Sidćn y Beirut-, para más tarde acometer la toma de las grandes y resistentes fortalezas de Kerak, Montreal/Shawbak, Safed y Belvoir, con las que, en ese año de 1187 quedaba reconquistada la parte sur de los territorios francos del reino de Jerusalén. Finalmente, en la primavera de 1188 el caudillo musulmán se lanzó a la conquista del condado de Trípoli y del principado de Antioquía, donde fueron asaltados y recuperados otros tantos enclaves fortificados -entre ellos Safita, Qalat Arime, Qalat Yahmur, Jabala, Laodicea/Lataquia, Qalat Sahyun/Saone, Bakas-Shoqor, Qalat Burzey, Darbsaq, etc. -43 .

Las consecuencias a largo plazo de las dos batallas mencionadas fueron diferentes dependiendo del contexto. En la Península lbérica el territorio perdido y sus enclaves estratégicos fueron pronto recuperados como consecuencia de las Navas, mientras en el Oriente Latino, Hattín significó el punto de inflexión hacia la definitiva expulsión de los francos que se produciría un siglo después. Sin embargo, de lo que no cabe duda es que la ocupación de los lugares fortificados de un espacio, fue la prolongación lógica de las victorias obtenidas en el campo de batalla, una forma de rentabilizar - con mayor o menor fortuna- ese gran esfuerzo militar mediante la dominación de las principales fortalezas del enemigo, a la postre la mejor manera de socavar los cimientos políticos de los rivales.

Pero además, hemos de ser conscientes del confuso espectro de motivaciones que inclinaron a los ejércitos medievales a tener como objetivo primordial de sus operaciones la conquista de las plazas fortificadas; motivos económicos en el caso de los guerreros a soldada y de los mercena-

42 Runciman, S.: Historia de las Cruzadas..., II, pp. 424-425 y III, pp. 17-18; LYons, M.C., y JACKSON, D.E.P.: Saladin..., pp. 283 y 286.

43 Para seguir con mayor precisión el itinerario del conquistador por las tierras costeras y del norte de Siria, vid. HuYGENS, R.B.C.: "La campagne de Saladin en Syrie du nord (1188)", en Actes du Colloque Apamée de Syrie, Eds. Janine y Jean Ch. Balty, Bruselas, 1972, pp. 273-283. 
rios 44 ; un componente estratégico y político que excitaba a los gobernantes ${ }^{45}$ y pontífices; o un móvil ideológico que conducia las acciones de los hermanos de las órdenes militares fueron causas recurrentes. La adecuada combinación de éstas y otras intenciones convirtieron a los castillos en esos objetivos preferentes de los que hemos hablado.

Cambiando de punto de vista, nos parece interesante esbozar otras líneas del papel desarrollado por las fortalezas dentro de estrategias eminentemente defensivas, $y$ en concreto en tanto que instrumentos capaces de vigilar o defender las principales vías de comunicación.

La asociación de castillos y caminos es lógica por definición, y numerosos autores han reflexionado sobre este hecho, bien desde el punto de vista económico - a causa de la rentabilidad que proporcionaba el control comercial y fiscal de una ruta frecuentada-, político y estratégico - debido a las evidentes ventajas defensivas que comportaba el control de los accesos al territorio enemigo-, o teniendo en cuenta acontecimientos sociológicos tan significativos del medievo como fueron las peregrinaciones. Pues bien, estas circunstancias concurrieron en los dos espacios geográficos que analizamos, donde podemos apreciar a menudo una estrecha relación entre las líneas de comunicaciones y los enclaves castrales.

J. González establecia hace tiempo una interesante relación entre los dos elementos de los que nos ocupamos - fortalezas y caminos-, concluyendo que la falta de fortificaciones en una región significaba una deficiente red de comunicaciones, y por tanto que ese espacio en cuestión carecia de valor estratégico ${ }^{46}$. Teniendo en cuenta estas palabras, quizás demasiado tajantes, podemos afirmar que los territorios francos, al igual que las tierras hispanas en disputa con el Islam, presentaron un importante interés estratégico así como abundantes caminos que vigilar, y por ende manifestaron una alta densidad castral. Pero pasemos a mencionar algunos ejemplos concretos.

44 En este sentido vid. Garcia FiTz, F.: Castilla y León frente al Islam..., pp. 78-89.

45 En algunas ocasiones los monarcas castellanos impulsaron el avance de la reconquista, mediante la donación a sus súbditos -en concreto a las órdenes militares- de todos aquellos territorios todavía en poder musulmán, que fueran capaces de recuperar. Es el caso de la concesión hecha por Alfonso Vill a la orden de Calatrava en 1173, de "omne castellum quod de Sarracenis deinceps quolibet modo adquirere potueritis" (GONZALEZ, J.: Alfonso VIII, II, doc. n. ${ }^{183}$, p. 306). En tiempos de Fernando lil se puede constatar una realidad semejante, entre otros casos en el momento de la concesión a los santiaguistas del castillo de Reina, todavia sin conquistar, en cuyo documento de donación el monarca advierte además que si antes de conquistarlo él mismo o la propia orden se llegara a una tregua con la ciudad de Sevilla, este castillo entraría en dicha tregua (GoNZÁLZ, J.: Reinado y diplomas de Fernando III, Córdoba, 1986, III, doc. n. ${ }^{2} 739$ ).

46 GonZÁLEZ, J.: Repoblación..., I, p. 322, en concreto acerca de los Montes de Toledo. 
En Tierra Santa muchos castillos y recintos defensivos se encontraban directamente vinculados con las rutas que conducían a los peregrinos a Jerusalén y a otros santos lugares, fuertes que con frecuencia se encontraban defendidos por las órdenes del Temple o del Hospital ${ }^{47}$. Es el caso, por ejemplo, del castillo de Safed, obra templaria que no sólo se encargó de defender un frecuentado camino de ataque hacia Acre, vía tradicional de hostigamiento de esta ciudad por parte de sarracenos, beduinos y turcómanos, sino que la erección de tan relevante fortificación protegía un dilatado distrito en el que era posible visitar algunos lugares bíblicos ${ }^{48}$.

La defensa de peregrinos en ruta por los caminos de oriente también subyace entre las funciones desempeñadas por Beitenuble, una fortaleza situada entre la llanura costera y Jerusalén, "presidium solido fundant opere ad tutelam transeuntium peregrinorum", que además servía para vigilar las peligrosas incursiones procedentes de la costera ciudad de Ascalón 49.

Eydoux, sin embargo, se cuestiona el cometido de algunas importantes fortalezas francas como la mencionada Safed, Chastel-Pèlerin/Athlit, el Crac de los Caballeros, o Qalat Sahyun, al respecto del control que pudieron ejercer sobre algunos caminos interiores o sobre vias proyectadas hacia las fronteras externas de los territorios cristianos, puesto que a ese supuesto papel vinculado a las rutas de comunicación se añaden otras muchas facetas funcionales tanto o más determinantes en su existencia 50 .

47 La ubicación de fortificaciones templarias en los caminos de peregrinación entre Jerusalén y el Jordán, o entre Jersualén y Jafa han sido documentados y estudiados por PRINGLE, ID.: “Templar Castles on the Road to the Jordan", en The Military Orders: Fighting for the Faith and Caring for the Sick, ed. M. Barber, Variorum, 1994, pp. 148-166; ID.: "Templar castles between Jaffa and Jerusalem", en The Miitary Orders. Volume 2. Welfare and Warfare, ed. H. Nicholson, Ashgate, 1998, pp. 89-109; tambien vid. FOREY, A.: The Military Orders..., p. 59.

48 La edificación del castillo "est repugnaculum et obstaculum ne ad nocendum publice transire audeant a flumine Iordanis usque Accon, nisi esset maxima multitudo, et ab Accon usque Saphet vadum secure honerati sumarii ef quadrige", y su presencia intimidatoria permitía que pudieran ser visitados "loca tamosa que sunt in districtu castri Saphet, ut cisterna loseph (...) et civitas Capharnaum...". Pero además, Safed proporcionaba a su entorno un elevado grado de seguridad que permitia que "agricultura et terre colonia libere ab omnibus exerceturs (HUYGENS, R.B.C.: De constructione castri Saphet. Construction et fonctions d'un château fort franc en Terre Sainte, Amsterdam-Oxford-Nueva York, 1981, pp. 42-43.

49 Beitenuble/castrum Arnaldi corresponde con el castillo de Gibelin “...ibi enim in faucibus montium inter angustias inevitabiles maximum iter agentibus solebat imminiere periculum, Ascalonitis subitas irruptiones illic facere consuetis" WILLELMI TYRENSIS ARCHIEPISCOPO: Chronicon, ed. R.B.C. Huygens, Corpus Christianorum, Continuatio Medievalis, LXIII A, Turnholt, 1986, Lib. XIV, cap. 8, p. 640. [En adelante Crónica de Guillermo de Tiro]).

50 En el caso Chastel-Pèlerin, al igual que el ya referido de Safed, la riqueza agrícola de las tierras bajo sus dominios constituian motivos de peso para el establecimiento de tan importantes construcciones. Por su parte, el Crac se erigió como la base de operaciones desde la que los hospitalarios aguijoneaban frecuentemente la región de Hama y Homs, situadas al otro lado de las montañas. $Y$ Saone se convirtió en un relevante emplazamiento capaz de controlar, por un lado la zona costera de Lataquia y por otro el valle interior del Orontes, de ahi su monumentalidad poco acorde con el simple cometido de centinela de un camino (EYDoux, H.-P.: Les Châteaux du Soleil.., pp. 228-229). 
En la Península Ibérica, algunos autores también han reflexionado acerca de la manifiesta relación existente entre los itinerarios de comunicación y ciertas estructuras castrales vinculadas a su defensa o control ${ }^{51}$, y a tenor de sus resultados los ejemplos podrían ser muchos. Sin embargo, nos gustaría exponer un caso que además establece numerosas perspectivas de análisis posibles, nos referimos a la relevante relación entre algunas fortalezas ubicadas en las orillas del río Tajo y el control ejercido desde ellas, no sólo del propio valle como lógico acceso desde la zona levantina hacia el interior de la Meseta, sino de varios caminos que atravesaban el río en sentido perpendicular norte-sur, poniendo en contacto la Transierra y la Mancha.

Los enclaves de Oreja y Alharilla, junto a otras fortificaciones menores del entorno, pasaron con la conquista cristiana a integrarse entre los castillos más avanzados del pujante reino castellano, capitalizando en puntos localizados el tráfico de personas y mercancias que bajaban por el río o que lo pretendían cruzar. La orden de Santiago se hizo pronto con el dominio de tan relevante área estratégica -a partir de 1171 que es cuando se documenta la donación de Oreja 52 , y al menos desde 1200 sabemos del cobro de un portazgo en este castillo con aranceles muy similares a los que apreciamos en el importante nudo comercial de Alharilla ${ }^{53}$, ingresos derivados del paso del Tajo que allí se realizaba a través de una barca.

La fortaleza de Alharilla ${ }^{54}$, por su parte, constituía otro de los lugares en los que se canalizaba el tráfico comercial y ganadero de este tramo del río ${ }^{55}$,

51 La mayoría de las referencias se refieren sin embargo al mundo andalusi: FranCO SANCHEZ, F: Castillos y defensas andalusies en la Mancha Oriental, Alicante, 1995; ID.: Estudio de Ios espacios viales y de los espacios defensivos de la Mancha Oriental en el periodo islámico, Madrid, 1996; HERNANDEZ JIMÉNEZ, F.: «El camino de Córdoba a Toledo en la época musulmana", Al-Andalus, 24, 1 (1959), pp. 1-62; MALALANa, A.; MARTinez, S.; SAEZ, F.: “La ruta del Jarama y su entorno en época andalusí", en Origenes históricos de la actual Comunidad Autónoma de Madrid. La organización social del espacio en la Edad Media, 1, Madrid, 1995, pp. 139-181; Sáez, F.; Malalana, A.; Martinez, S.: "Poblamiento y red viaria en la Marca Media. Un comienzo de aproximación (ss. VIIr-X)", en Actas del Congreso de Arqueologia Peninsular de Zamora, vol. IV, Madrid, 1999, pp. 537-554; LluL, P.; HUETE, M.; MoLINA, J.: "Un itinerario musulmán de ataque a la fronter castellana en el sigio $x$ : fortalezas, castillos $y$ atalayas entre Medinaceli y San Esteban de Gromaz", Castillos de España, 93 (1987), pp. 3-14; RuIBAL, A.: «Arquitectura militar y vías de comunicación: caminos de Córdoba a Toledo en los siglos ix-xill y sus sistemas defensivos", en Los Caminos y el Arte. Actas del VI Congreso Español de Historia del Arte, vol. II, Santiago de Compostela, 1989, pp. 17-31.

52 1171 , septiembre 11. Montealegre. Pub. GonzALEZ, J.: Alfonso VIII, II, doc. n. ${ }^{\circ}$ 162, pp. $275-276$. Vid. Palacios Ontalva, J.S.: Fortalezas santiaguistas. La orden en la ribera del Tajo (siglos XII-XVI) (en prensa).

53 Martín, J.L.: "Portazgos de Ocaña y Alharilla", Anuario de Historia del Derecho Español, 32 (1962), pp. 519-526.

54 Entregada a la orden el 7 de febrero de 1172 (Pub. GonzÁleZ, J.: Alfonso VIII, II, doc. n. ${ }^{9} 168$, pp. 284-286).

55 Alharilla se convirtió en eje de los intercambios de un amplio sector de Castilla, puesto que desde Ávila a Guadalajara, pasando por Valladolid, Medina del Campo, Arévalo, Segovia y Buitrago, 
y allí parece que tempranamente el vado fue convertido en un puente para facilitar el paso de ganados trashumantes, aunque de este puente nada sabemos, siendo sustituido por otro que se edificó en Fuentidueña y que también se perdió ${ }^{56}$. Pero de la desaparecida fortaleza de Alharilla destaca como a su alrededor parece que se desarrolló una amplia oferta de servicios relacionados con este flujo constante de hombres, ganados y mercancías, y su importancia creció de forma considerable hasta convertir el castillo en un asentamiento de mediano tamaño cuya defensa había que garantizar. Es posible que entonces se construyeran toda una serie de infraestructuras asociadas, tales como el hipotético puente sobre el Tajo, una azuda "que est sub muro istius castelli de Alfarella», y la alberguería, que estaba también "iuxta vadum Alfarella" 57 .

Los castillos citados, además de cumplir con sus funciones puramente castrales, asegurando el asentamiento colonizador de pobladores castellanos y soportando el peso de la lucha fronteriza durante algunos años ${ }^{58}$, se localizaron en relevantes nudos de comunicaciones, caminos, valles, puentes o vados, y por tanto sus actividades de vigilancia o control tuvieron mucho que ver con la defensa de dichas rutas. A esas funciones defensivas se adhieren múltiples facetas funcionales a propósito del valor estratégico y comercial que tuvieron los caminos medievales. Fue precisamente esa polivalencia la caracteristica más sobresaliente de un alto número de fortificaciones cruzadas e hispanas, puesto que a su condición de herramienta de vigilancia de un punto fronterizo estratégico o de una vía, se unieron otras atribuciones de carácter asistencial, fiscal y militar mucho más complejas que las relacionadas con una simple atalaya de observación.

los comerciantes estaban obligados a pasar por este punto, en el que además se canalizaba parte del paso de los ganados trashumantes hasta las montañas de Toledo, Cuenca y Huete, y sobre los que también se estableció un portazgo (MARTiN, J.L.: Orígenes de la Orden Militar de Santiago (11701195), Barcelona, 1974, doc. n.. 58, pp. 232-234; ID.: “Portazgos de Ocaña y Alharilla”, pp. 519-526).

56 A pesar de ello, todavia las Relaciones de la villa de Fuentidueña citan su existencia y la de una barca que atravesaba el Tajo «...y en el dicho rio de Tajo junto a la dicha villa esta la barca que dicen de Fuentidueña, porque donde se pasa el dicho rio e mas arriba de ella junto a la mesma barca esta una puente de madera que sirve de pasar los ganados cuando van a Estremo e vienen de la sierra, la cual dicha barca e puente son de don Luis de Requesens, comendador mayor de Castilla..." (VINAS, C., y PAZ, R.: Relaciones Histórico-Geográficas-Estadísticas de los pueblos de España hechas por iniciativa de Felipe II, Provincia de Madrid, Madrid, 1949, p. 276).

57 GonzAlez, J.: Alfonso VIII, II, doc. n. 9 95, pp. 162-165. Una especie de mesón, producto de la evolución de una hipotética albergueria primitiva de carácter asistencial, que además de alojamiento proporcionaba servicios de almacenaje y mediación en los negocios (vid. CARRERo Pérez, L.M.: El castillo y la villa de Fuentidueña de Tajo, Madrid, 1990, pp. 26-27).

58 García Fitz, a pesar de poner en duda la eficacia orgánica de las defensas del valle del Tajo, fundamenta en esos castillos el éxito de cierta estrategia defensiva que consiguió frenar el enorme impulso de las incursiones almohades de 1196 y 1197 (Castilla y León frente al Islam..., pp. 201-203). 


\subsection{Castillos contra castillos}

De la misma forma que Alfonso $X$ consideraba "los castiellos" como instrumentos esenciales en la defensa del reino, en su obra el Setenario podemos encontrar alusiones que nos evocan una faceta más agresiva de las fortalezas castellanas, "buenas para guerrear los omnes en tiempo de la guerra» 59 . Entramos, así, a considerar el papel ofensivo de las fortificaciones dentro de un contexto de guerra santa en la que estos elementos pudieron ejercer múltiples funciones punitivas contra los fundamentos de un poder rival, también asentado por su parte en la seguridad que le otorgaban las fortalezas bajo su dominio. Recurriendo de nuevo a las palabras del Rey Sabio, los castillos sirvieron eficaz y activamente en una estrategia para "ganar la tierra" 60 y no sólo para guardarla.

Las fortificaciones en tanto que herramientas ofensivas y de marcada potencialidad agresiva desdoblan sus posibilidades de ejercer un ataque entre los dos componentes que forman su realidad, nos referimos por un lado a la materialidad arquitectónica del castillo como tal, y por otro a la guarnición que lo ocupa ${ }^{61}$. Pero, frente a ciertas posturas que todavia atribuyen a los edificios el papel de meros reductos desde los que una hueste podía desplegar una faceta ofensiva más marcada, por nuestra parte consideramos que cada uno de los dos elementos citados son capaces de manifestar ese carácter combativo.

La presencia física de una fortaleza a la vista del enemigo o la sola percepción que el otro ha obtenido el control de un lugar emblemático o de relevancia estratégica objetiva, creemos que constituye un arma que penetraba profundamente en la mentalidad defensiva de los rivales con la misma fuerza que la incursión de un contingente armado en su territorio. Pero además, hubo enclaves cuya ubicación, disposición táctica y actividad les convirtieron en auténticas amenazas para otros asentamientos, y por tanto se revelaron como armas efectivas en poder del enemigo. Si a este poder de la arquitectura militar sumamos los evidentes rasgos ofensivos de la guarnición que usaba estos puntos fuertes como bases de operaciones desde las que lanzar sus golpes de mano, la actividad bélica capaz de ser desarrollada por las fortalezas es innegable, y se hace obligatorio revisar viejas percepciones de los castillos medievales como simples refugios ante una amenaza externa 62 .

59 Setenario, Ley X, p. 20. Vid. GARCiA FITZ, F.: Castilla y León frente al Islam..., p. 204.

60 Ibidem, Ley X, p. 21.

61 La confusión entre las funciones ofensivas de las fortalezas y las que eran capaces de ejercer sus ocupantes fue en primer lugar aclarada por Stephen MoRiLlo (Warfare under the Anglo-Norman Kings, 1066-1135, Woodbridge, 1994, p. 94), y más tarde revisada por GARCiA FITz (Castilla y León frente al Islam..., p. 205).

62 Para esta revisión podemos echar mano de algunos documentos que se muestran explicitos acerca de la capacidad ofensiva de ciertas fortalezas: J.L. Martín incluye en su apéndice documental la 
Fortalezas y Guerra Santa. Un estudio comparado de algunos aspectos de...

En relación a la primera de las funciones desestabilizadoras que ciertos propugnáculos fueron capaces de explicitar, nos parece emblemático el significado agresivo que supuso para los musulmanes la posesión de Salvatierra por parte del enemigo, sobre todo cuando este enclave se mantuvo permanentemente a la vanguardia o incluso inserto, como un aguijón, en mitad de sus territorios.

Esta fortaleza, que tras la batalla de Alarcos debió engrosar la lista de los lugares perdidos o abandonados por los cristianos, fue recuperada en 1198 durante una incursión calatrava que dirigió el comendador mayor de la orden, Martín Martínez ${ }^{63}$, situándose a partir de entonces la sede principal de la orden en esta arriesgada posición, muchos kilómetros en el interior de territorio enemigo.

Así fue como Salvatierra se revistió de una aureola simbólica que la acompañó durante las primeras décadas del siglo XIII ${ }^{64}$, fama que fue conocida tanto entre cristianos como entre musulmanes y que, mientras para unos constituía el mejor acicate para reavivar la lucha frente al Islam, para los otros supuso la mayor de las afrentas.

En cualquier caso de lo que no queda duda es de la activa participación de esta fortaleza como principal base de hostigamiento del espacio controlado por los almohades, aunque a las operaciones de saqueo que se lanzaban desde Salvatierra hemos de añadir la no menos relevante agresión de carácter simbólico que suponía ese "punto negro que se alzaba sobre las llanuras del Islam» 65. Una "violencia real» y una callada "violencia simbólica» ${ }^{6}$ que conformaban dos caras de la misma realidad ofensiva en torno a dicho punto fuerte.

donación del castillo de Alcóncher, al sur de Badajoz, en "apte situm ad expugnandos Christi inimicos" (1171. Oruña. MARTín, J.L.: Orígenes..., doc. n. 50, pp. 223-224); en la donación que hizo Alfonso VIII del castillo de Consuegra, a favor de la orden del Hospital, se dice que éste se encontraba "a la frente de los moros" (1183, agosto 6. Palencia. GonZÁLEZ, J.: Alfonso VIII, II, doc. n. ${ }^{\circ} 409$, pp. 709-711); por su parte, cuando Alfonso IX de León dió a la orden de Calatrava la fortaleza y villa de Alcántara, la condición es que "semper guerram et pacem de ea quandocumque et quibuscumque mandavero faciatis" (1217, mayo 28. Toro. Gonzalez, J.: Alfonso IX, II, Madrid, 1944, doc. n. ${ }^{\circ} 346$, pp. 453-455. Sobre el concepto jurídico que este documento encierra es recomendable acudir a los numerosos ejemplos que expone GrassoTt, H.: «El deber y el derecho de hacer guerra y paz en León y Castilla», Cuadernos de Historia de España, LIX-LX (1976), pp. 221-296).

63 Rades y ANDRADA, F. DE: Chronica de Calatrava, fol. 21v.

64 Acerca del carácter simbólico que llegó a adquirir este castillo, es imprescindible acudir al trabajo de VARELA AGÜI, E.: "Salvatierra: simbolismo y poder en una fortaleza de la Orden de Calatrava", Actas del Simpósio Internacional sobre Castelos, Palmela (Portugal) (en prensa).

65 ABD al MunCIN AL-HIMyari: Kitab ar-Rawd al-Mitar Fi Habar al-Aktar, ed. y tradución de E. Lévi-Provençal, Leiden, 1938, según la traducción de HUICI MIRANDA, A., en Las grandes batallas de la Reconquista durante las invasiones africanas, Madrid, 1956 (Ed. facsimil, Granada, 2000), p. 314.

66 Vid. VARELA AGÜi, E.: «Salvatierra: simbolismo y poder...". 
Dejando de lado los múltiples ejemplos que sitúan a los castillos como las bases propicias desde las que organizar y proyectar pequeñas o grandes operaciones contra el territorio enemigo, ya glosados por otros autores ${ }^{67}$, donde sí que nos gustaría adentrarnos es en la complejidad funcional de ciertos castillos empleados precisamente para la conquista de otras fortalezas, los denominados castillos padrastro o de asedio ${ }^{68}$.

Entre los recursos ofensivos empleados en el asedio de fortalezas y ciudades amuralladas, cabe destacar el recurso de la expugnación por medio de otras fortificaciones, más o menos provisionales, pero que en cualquier caso podían ejercer una enorme presión sobre las defensas del objetivo marcado. Estas fortalezas de asedio se convertirian, en el transcurso de un cerco, en base desde la que lanzar sucesivas oleadas de asaltantes que después podían retornar a un emplazamiento seguro; también pudieron ejercer como reductos más alejados del objetivo, pero que de muy diferentes maneras podían ahogar la resistencia del enclave en cuestión -quebrantando sus comunicaciones, sus líneas de suministros o las posibilidades de recibir ayuda externa-; pero además, en algunas ocasiones, la proximidad entre las fortalezas ofensivas y la que repelía la agresión fue tan grande, que la misma presencia de aquella resultaba una amenaza palpable de por sí, y desde sus adarves fue posible incluso hostigar la plaza asediada $o$ a sus defensores.

En la línea apuntada, los territorios francos al igual que los peninsulares concentran muchos de los ejemplos de este tipo de fortalezas de clara orientación ofensiva, estableciéndose como primer elemento diferenciador una segregación entre las que formaron parte de estrategias a distancia encaminadas a agotar los recursos y capacidades de un enclave a través de una serie de fortificaciones no cercanas, es decir a través de castillos erigidos en su entorno, y por otro lado, aquellos puntos fuertes que se asocian a la conquista de una determinada fortificación y que, dada su proximidad, participaron de forma activa en su asedio.

Para el primero de los supuestos que planteamos, puede resultar gráfica la política de edificación de fortalezas que se siguió en torno a la ciudad de Ascalón por parte de los cruzados, que persiguieron con ella un doble objeti-

67 MARSHALL, Ch.: Warfare in the Latin East..., pp. 94 y 132-134; por su parte GARCIA FITZ aporta otras serie de ejemplos que ilustran de la misma forma esa capacidad agresiva de algunas fortalezas, en su faceta de sede de una guarnición con funciones ofensivas sobre el terreno (Castilla y León frente al /slam..., pp. 206-215). Del mismo autor vid. “Pora acreçentamiento de nuestros regnos. Las funciones ofensivas de los castillos de trontera", en La Fortaleza Medieval: Realidad y Símbolo, Murcia, 1998, pp. 75-89.

68 Recurrimos a la precisa definición que nos proporciona MORA-FIGUEROA, L. DE: Glosario de Arquitectura Defensiva Militar, Cádiz, 1994, p. 153, de la voz padrastro: "Punto dominante y a distancia de hostigamiento desde donde puede combatirse una plaza". 
vo: en primer lugar el control de las frecuentes cabalgadas que partían de esa ciudad y que presionaban los asentamientos francos de Jerusalén, Jafa y de la llanura costera, así como los caminos de peregrinación 69 , y en segundo término, el establecimiento de bases desde las que habilitar ataques contra dicha ciudad 70 . Entre 1136 y 1149 , por tanto, en la región fueron construidos diferentes enclaves de los que nos interesa resaltar su faceta más agresiva, aunque ésta no se pueda disociar de las funciones defensivas ya mencionadas, y de las que realizaron con posterioridad a la conquista de Ascalón como parte de la fontera meridional del reino de Jerusalén ${ }^{71}$. Estas fortalezas fueron Gibelin, Ibelin, Blanchegarde y Gaza ${ }^{72}$, y de ellas escribió Guillermo de Tiro - en el caso concreto de Gibelin-, que "...de vicino commodius hostium discurrentium refrenari posset impetus, et civitas frequentius impugnari, 73 .

Pero cuando quizás destacó más la orientación ofensiva de ciertos castillos, fue en el transcurso de operaciones en las que algún tipo de estructura castral se vio involucrada en el cerco y asalto directo a otra plaza, es decir, cuando cumplieron un cometido como verdaderos castillos padrastro. Este tipo de fortificaciones fueron construidas con el objetivo de cortocircuitar las comunicaciones de los sitiados con el exterior, para anular las posibles vías de huida o de llegada de refuerzos, e impedir a la vez el abastecimiento, aguada o forrajeo de un núcleo sometido a asedio.

No podemos olvidar, en este sentido, que las primeras construcciones militares de los francos en territorio sirio fueron precisamente este tipo de fortalezas de expugnación, levantadas apresuradamente durante el asedio de ciudades como Antioquia. Y fue en este lugar donde documentamos varias de estas fortalezas, en concreto las tres primeras que las tropas cruzadas decidieron erigir contra los poderosos muros de la ciudad: Malregard, la torre de la Mahommerie o de Raimundo y el castillo de Tancredo.

El asedio de Antioquía comenzó el 21 de octubre de 1097 y acabó con la capitulación de la ciudad el 3 de junio de $1098^{74}$, largos meses en los que se fue socavando progresivamente la resistencia de las defensas an-

69 Crónica de Guillermo de Tiro, Lib. XIV, cap. 8, p. 640. SmAlL, R.C., Crusading Warfare..., p. 211.

70 Evdoux, H.-P.: Les Châteaux du Soleil.., pp. 187 y ss. y 224-227, a este tipo de fortalezas el autor llama châteaux de blocus; Small, R.C.: Crusading Warfare..., pp. 211-213; ID.: "Crusaders' Castles of the Twelfth Century", pp. 140-141, habla sin embargo del interesante concepto de aggressive defence, cuando alude al sentido con el que fueron levantadas.

71 Ellenblum, R.: Frankish rural settlement in the Latin Kingdom of Jerusalem, Cambridge, 1998, pp. 16-17; Small, R.C.: Crusading Warfare..., p. 211, quienes, además de ponderar su papel defensivo en el sur del reino, considera estos enclaves como semilla de asentamientos posteriores.

72 Vid. Kennedy, H.: Crusader Castles, Cambridge, 1994, pp. 30-33.

73 Crónica de Guillermo de Tiro, Lib. XIV, cap. 8, p. 639.

74 France, J.: Victory in the East..., pp. 197-296, en especial pp. 236 y ss.; BradBury, J.: The Medieval Siege, pp. 109-114. 
tioquenas, en gran medida a través del desgaste que suponían estos padrastros vigilando sus accesos y comunicaciones. El 23 de noviembre de 1097 se comenzaba a levantar sobre una colina la torre de Malregard, con el fin de controlar la salida de los defensores hacia el valle del Orontes por la Puerta de San Pablo - al norte- y para evitar el ataque de guarniciones musulmanas contra el campamento de Bohemundo ${ }^{75}$. Para dominar el acceso al puente fortificado que se encontraba al oeste de las murallas, Raimundo de Tolosa propuso la construcción —en marzo de 1098-, de otra fortaleza en el lugar que ocupaba un antiguo cementerio musulmán y una mezquita, interrumpiendo de ese modo una hipotética salida de los defensores hacia el mar ${ }^{76} . Y$ por último, a primeros de abril los francos emprendieron la edificación de un nuevo fuerte en una colina próxima donde se hallaba un antiguo monasterio, el llamado castillo de Tancredo, fortaleza que se hallaba a escasa distancia de la Puerta de San Jorge y con la que los atacantes tenían la intención de completar el cerco de la ciudad 77 .

Por desgracia nada se conserva hoy de aquellas primeras arquitecturas militares cruzadas, desaparecidas a buen seguro por la propia inconsistencia que debieron presentar - dada la provisionalidad y rapidez con la que fueron levantadas - , sin embargo, parece indudable atribuirles buena parte del éxito obtenido por los cruzados en algunas operaciones de conquista, sobre todo en el caso de grandes ciudades cuyo cerco requería acciones permanentes de desgaste más que asaltos puntuales contra unas bien pertrechadas murallas. Pero pasemos ahora a considerar algunos casos hispanos.

Acerca del empleo de fortificaciones en el curso de operaciones de conquista, el contexto bélico peninsular durante el siglo XII proporciona asimismo numerosos casos dignos de mención. Nos referiremos en primer lugar a la conocida plaza de Mora, que tras ser arrebatada en 1138 a su alcaide, Munio Alfonso, se convirtió en base de numerosos ataques musulmanes que azotaron la cercana tierra de Toledo ${ }^{78}$. Pues bien, ante la amenaza real que constituía el enclave, Alfonso VII ordenó la construcción de un nuevo castillo junto a Mora la vieja, la llamada fortaleza de Peña Negra, que fue entregada a Martín Fernández, y cuya misión consistía en limitar la capaci-

75. Runciman, S.: Historia de las Cruzadas..., I, p. 212; France, J.: Victory in the East..., pp. 211-212 у 229-232.

76 Runciman, S.: Historia de las Cruzadas..., 1, pp. 219-220; France, J.: Victory in the East..., pp. 140, 231-232 y 254.

77 Runciman, S.: Historia de las Cruzadas..., I, p. 220; France, J.: Victory in the East..., pp. 231-232 y 254-255.

78 Chronica Adefonsi Imperatoris, pp. 110-111. 
Fortalezas y Guerra Santa. Un estudio comparado de algunos aspectos de...

dad de maniobra y agresión de la guarnición de aquella 79 . El objetivo parece que se cumplió ${ }^{80}$, y poco después -en 1144- la propia fortaleza de Mora sucumbió al asalto del Emperador 81 , aunque al menos hasta 1224 parece que ambas estructuras castrales convivieron en sus emplazamientos respectivos, ya que en esa fecha Fernando III ordena la destrucción de "illas turres de Rupe nigra in colle de Mora" considerando que podían suponer un peligro para el castillo primitivo ${ }^{82}$.

Del análisis de los datos expuestos sobre los castillos de Mora y Mora la vieja, tal y como figuran en la bula de confirmación concedida a la orden de Santiago en $1175^{83}$, se desprenden sin embargo algunas dudas que no nos sentimos capaces de resolver: en primer lugar, ponemos en duda que los escasos restos que se conservan en las proximidades del actual castillo correspondieran en algún momento a un enclave que las fuentes calificaron de melius et fortius; pero además, si en 1175 el papa Alejandro III confirma, entre otras muchas, las dos posesiones citadas, por qué en la concesión a la orden de Santiago de la fortaleza todo parece indicar la existencia de una sola de ellas ${ }^{84}$, y sobre todo, por qué años más tarde Alfonso VIII entregó de nuevo a la orden un castillo llamado de Peña Negra, que se suponía en su poder ya en $1175^{85}$.

Sea como fuere, el caso del padrastro de Mora no es el único, y podemos encontrar nuevos paralelos de fortalezas concebidas para la conquista sin salirnos siquiera de los señoríos de la orden de Santiago, institución a la que también perteneció el enclave de Oreja por el que ahora nos interesamos.

Este castillo ubicado en la ribera del río Tajo, tras una campaña que dejó una importante huella cronística ${ }^{86}$ y cuyas consecuencias político-territoriales no resultaron menos relevantes ${ }^{87}$, fue recuperado por las tropas caste-

79 La Crónica del Emperador lo relata de la siguiente manera: "Imperata vero, audiens quod capta esset Mora, abiit illuc et fabricavit contra faciem Morae aliud castellum quod dicitur Penna Nigra, melius et fortius, et munivit illum militibus et peditibus multum bellicosis et sumptibus; et dedit illum cuidam principi, cuius nomen erat Martinum Fernandi, qui quotidie debellabat eos, qui erant in Mora, usque imperator cepit eum" (Chronica Adefonsi Imperatoris, p. 111).

80 GonzÁlez, J.: Repoblación, I, p. 146.

81 "Fue presa Mora en el mes de abril, era MCLXXXI"» (Anales Toledanos I, ed. Enrique Flórez. España Sagrada. Theatro Geographico-histórico de la Iglesia de España, tomo XXIII, 1767, p. 389).

82 Pub. González, J.: Reinado y diplomas de Fernando III, III, doc. n. ${ }^{\circ}$ 192, p. 233.

83 Vid. Martin, J.L.: Orígenes..., doc. $n .{ }^{9} 73$, pp. 248-254, asi como la traducción castellana que incluye RADES Y ANDRADA, F. DE: Chronica de Santiago, fols. $12 \mathrm{v}-15 \mathrm{v}$.

84 Pub. Martín, J.L.: Origenes..., doc. n. ${ }^{9} 45$, pp. 217-218.

85 Pub. IBIDEM: doc. n. 9113 , pp. 297-298.

86 La Chronica Adefonsi Imperatoris dedica un espacio considerable a la descripción del asedio, negociaciones y concluyente asalto a la fortaleza (pp. 113-123).

87 Oreja se habia destacado entre los años 1113 y 1139 como base de operaciones para los contingentes almorávides que acosaban Toledo. Su conquista se convirtió entonces en el primer triunfo de las armas cristianas en el Tajo, y en punto de inflexión a partir del que se alejó definitivamente la frontera de las márgenes de este río, vid. PALACIOS ONTALVA, J.S.: Fortalezas santiaguistas... (en prensa). 
llano-leonesas a finales de octubre de $1139{ }^{88}$. Pero a lo largo del dilatado cerco que sufrió la plaza, nos llama la atención un hecho que prácticamente ha pasado desapercibido, nos referimos a la noticia de la construcción de un castillo en el entorno inmediato a Oreja destinado al hostigamiento permanente del recinto principal, y por tanto con evidentes características ofensivas. De la existencia de este enclave sabemos por ser el lugar desde el que Alfonso VII despacha algunos documentos entre julio y septiembre de 1139, in illo castello novo quod fecit imperator predictus iuxta Aureliam quando eam tenebat obsesam ${ }^{89}$.

Es decir, estaríamos hablando de la posible presencia de un padrastro 0 de algún tipo de fortaleza de asedio acerca de la que ningún otro dato podemos aportar, salvo la escueta mención que en su día hizo P. Madoz a la existencia en Oreja de dos castillos, uno conservado y otro destruido 90 .

Otros autores han glosado ya algunos ejemplos más de este tipo de fortificaciones de asedio, son los casos de Alcalá, Coria, Castilnovo contra Molina, Calatrava la Nueva frente a Salvatierra, San Pablo contra Montiel, además de los casos citados de Mora y Oreja, que menciona J. González ${ }^{91}$, - la posibilidad de que el castillo de Miraflores fuera levantado como padrastro del de Piedrabuena, como sugirió Corchado ${ }^{92}$. Esta reiteración con la que aparecen casos similares en la documentación contemporánea nos lleva a creer que, inserto en la realidad castral peninsular y entre las funciones que con cierta normalidad desempeñaron los castillos hispanos dentro de un contexto de guerra santa, se encontraba este papel ofensivo orientado hacia la conquista de otros puntos fuertes.

Como desde un principio manifestábamos, las fortificaciones que jalonaron las principales áreas de fricción entre el Islam y la Cristiandad concentraron gran parte de la actividad bélica en un momento en el que los enfrentamiento abiertos entre dos ejércitos fueron poco frecuentes. La lucha por el control de estos puntos fuertes constituyó el primer eslabón en la lu-

88 Postremo autem die mensis, summo mane, datum est castellum et impletae sunt turres militum christianorum, et elevata sunt vexilla regalia super excelsam turrem (Chronica Adefonsi Imperatoris, p. 120).

89 Cit. GonzÁLEZ, J.: Repoblación, I, nota n. 9, p. 141

9. Este autor menciona en su descripción del emplazamiento, « un castillo regularmente conservado, otro destruido a alguna distancia" (MADOz, P.: Diccionario Geográfico-Estadístico-Histórico de España y sus posesiones de Ultramar, Madrid, 1950, XII, p. 302).

91 GonzÁlez, J.: Repoblación, I, pp. 285 y 354-355; ID., Repoblación, II, pp. 201-202, donde además alude al topónimo relativamente frecuente que hace referencia a las "torres de mal vecino", con evidentes connotaciones en la línea que apuntamos.

92 Corcahado Soriano, M.: El Campo de Calatrava. Los pueblos, Ciudad Real, 1982, pp. 371 y 377. 
cha por el dominio del territorio. En definitiva, si la pérdida de fortalezas supuso para unos el principio del progresivo quebranto de sus bases económicas, políticas, demográficas, y por supuesto militares, en otras circunstancias más favorables se encuentran aquellos poderes capaces de conquistar y mantener un alto número de puntos estratégicos fortificados, puesto que detrás de una inicial implantación militar en ellos, se fomentó normalmente una expansión territorial y las consiguientes labores de colonización que apuntalaban definitivamente el dominio sobre el espacio.

Detrás de un propósito táctico encaminado a la adquisición de estas fortalezas, hemos de buscar por tanto planteamientos políticos de mayor profundidad, objetivos de consolidación política y territorial de unas áreas geográficas marcadas por la inestabilidad, la violencia de trasfondo religioso y las duras condiciones de vida en la frontera.

Una vez abandonado el contexto bélico en el que nos hemos movido a lo largo de las páginas anteriores, entramos en un nivel en el que los núcleos fortificados se revistieron de nuevas y más complejas atribuciones funcionales. Sirvieron entonces como los necesarios apoyos defensivos de unos espacios todavía amenazados, pero además cumplieron su papel como ejes para cristalizar a su alrededor el poblamiento, como centros administrativos y sedes de la autoridad alrededor de los cuales crecieron pequeños señorios, o gracias a los que fue posible el funcionamiento de una estructura orgánica al servicio de un poder más amplio.

Sin embargo, éstas y otras facetas funcionales adquiridas progresivamente por las fortalezas constituyen objetos de estudio que rebasan los límites del presente trabajo. 